GA-A16034

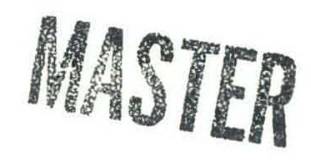

\title{
TITANIUM GETTERING IN DOUBLET III
}

J. S. de GRASSIE, R. CALLIS, G. CAMPBELL, J. GARCIA, E. LEDIN, C. MEYER, J. MILLER, P. PETERSEN, J. SMITH R. STAV, T. TAYLOR, and THE DOUBLET III GROUP

GENERAL ATOMIC COMPANY
SAN DIEGO, CALIFORNIA 92138

and

M. NAGAMI AND THE JAERI GROUP

JAPAN ATOMIC ENERGY RESEARCH INSTITUTE

AUGUST 1980

\section{GENERAL ATOMIC COMPANY}




\section{DISCLAIMER}

This report was prepared as an account of work sponsored by an agency of the United States Government. Neither the United States Government nor any agency Thereof, nor any of their employees, makes any warranty, express or implied, or assumes any legal liability or responsibility for the accuracy, completeness, or usefulness of any information, apparatus, product, or process disclosed, or represents that its use would not infringe privately owned rights. Reference herein to any specific commercial product, process, or service by trade name, trademark, manufacturer, or otherwise does not necessarily constitute or imply its endorsement, recommendation, or favoring by the United States Government or any agency thereof. The views and opinions of authors expressed herein do not necessarily state or reflect those of the United States Government or any agency thereof. 


\section{DISCLAIMER}

Portions of this document may be illegible in electronic image products. Images are produced from the best available original document. 
This report was prepared as an account of work sponsored by an agency of the United States Government. Neither the United States Government nor any agency thereof, nor any of their employees, makes any warranty, express or implied, or assumes any legal liability or responsibility for the accuracy, completeness, or usefulness of any information, apparatus, product, or process disclosed, or represents that its use would not infringe privately owned rights. Reference herein to any specific commercial product, process, or service by trade name, trademark, manufacturer, or otherwise, does not necessarily constitute or imply its endorsement, recommendation, or favoring by the United States Government or any agency thereof. The views and opinions of authors expressed herein do not necessarily state or reflect those of the United States Government or any agency thereof. 
GA-A16034

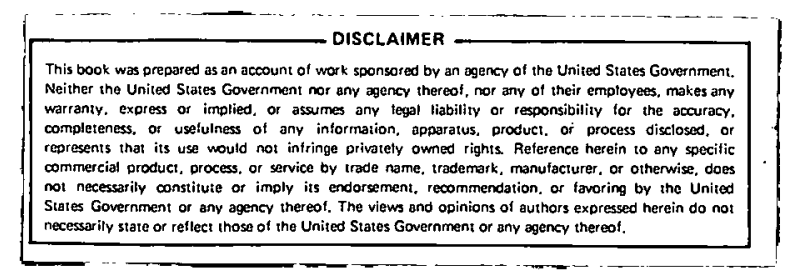

\title{
TITANIUM GETTERING IN DOUBLET III*
}

\author{
J. S. de GRASSIE, R. CALLIS, G. CAMPBELL, J. GARCIA, \\ E. LEDIN, C. MEYER, J. MILLER, P. PETERSEN, J. SMITH \\ R. STAV, T. TAYLOR, and THE DOUBLET III GROUP
}

\author{
GENERAL ATOMIC COMPANY \\ SAN DIEGO, CALIFORNIA 92138
}

\author{
and \\ M. NAGAMI AND THE JAERI GROUP
}

\section{JAPAN ATOMIC ENERGY RESEARCH INSTITUTE}

This is a preprint of a paper presented at the 27th National Vacuum Symposium of the Amierican Vecuum Socioty, Octoher 14-17, 1980, Detroit, Michigan, and to be published in the Journal of Vacuum Science and Technology.

"Work supported by the Department of Energy and the Japan Atomic Energy Research Institute,

Contract Numbers DE-ATO3-76ET51011 and DE-ATO3-80ET51019.

GENERAL ATOMIC PROJECTS 3235. and 3313.

AUGUST 1980

\section{GENERAL ATOMIC COMPANY}




\section{ABSTRACT}

The application of mild titanium gettering in the Doublet III tokamak has led to a significant improvement in the obtainable operating regimes and discharge parameters for all of the many plasma cross-sectional shapes studied. With gettering, low-z impurities and radiated power are greatly reduced. The maximum line averaged electron density has increased 50\% $\left(\bar{n} \overline{m a x}_{\max } \sim 1 \times 10^{20} / \mathrm{m}^{3}\right)$, corresponding to a Murakami coefficient of nearly 6 . 


\section{INTRODUCTION}

Titanium gettering is now an established technique for reducing the low-z impurity content present in a tokamak discharge. ${ }^{1}$ Typically, titanium is evaporated between plasma discharges onto some portion of the vacuum vessel wall or perhaps special panels. The presence of the titanium is then observed to significantly reduce the level of low-z impurities in a discharge, especially that of oxygen. This reduction is apparently due to a decrease in impurity release from the wall and limiter surfaces arising from; (1) the relatively strong chemical bonding of the impurity to the titanium, (2) the shielding of the wall from plasma bombardment by the freshly deposited titanium surface, and (3) by decreasing the rate of metallic oxide reduction beneath the titanium surface due to a lower atomic hydrogen concentration. ${ }^{2}$ This latter effect is promoted by the high surface recombination rate for hydrogen on titanium.

The Doublet III tokamak (Fig. I) is operated by General Atomic company (GA) for studies of vertically elongated plasma cross-sections by research groups from GA and the Japan Atomic Energy Research Institute (JAERI). Stable ohmically heated discharges with a duration of up to 0.8 seconds have been obtained with a variety of plasma shapes. 3,4 The JAERI group has produced diverted and non-diverted dee-shaped plasmas in the upper half of the machine and the GA group has produced doublet, droplet (two separated lobes), and expanded boundary ${ }^{5}$ shapes. Record values of plasma current $\left(I_{p}\right)$ have been achieved: $1.0 \mathrm{MA}$ in a dee and $2.2 \mathrm{MA}$ in a doublet at a toroidal magnetic field $\left(\mathrm{B}_{\mathrm{T}}\right)$ of $2.4 \mathrm{~T}$.

Prior to the use of titanium gettering the principal methods of impurity control were standard low power discharge cleaning ${ }^{6}$ and gas 


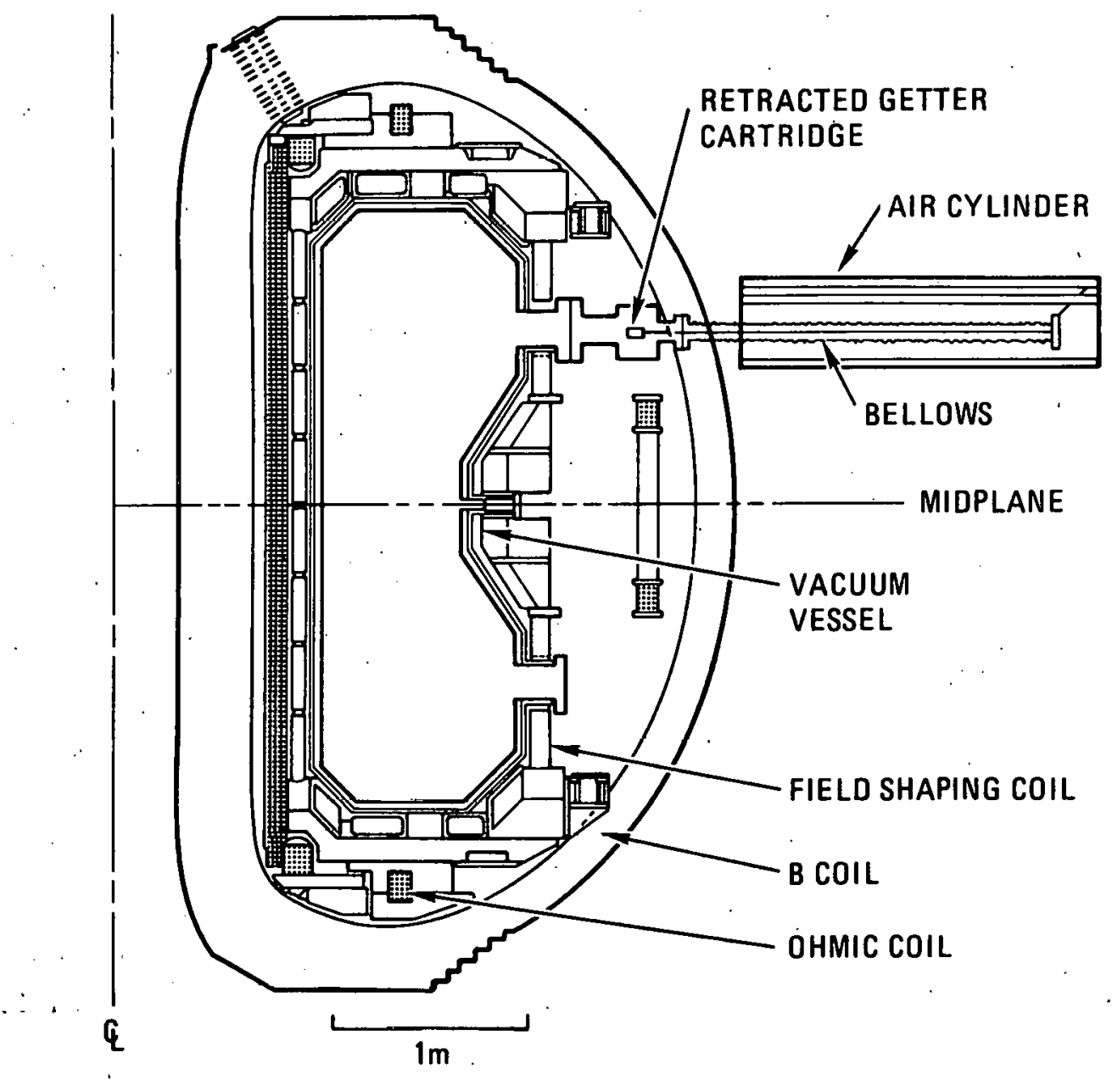

Fig. 1. Cross section of Doublet III showing coil systems and an outline of one of the two gettering mechanisms 
puffing. 7 During this period clean surface conditions were achieved for the Inconel vacuum vessel and limiters. Plasmas with relatively low effective ionic charge $\left(z_{\text {eff }}\right)$ and a high line average electron density $\left(\bar{n}_{e}\right)$ were obtained.

The use of mild titanium gettering further reduced the impurity level, primarily through a large reduction in the oxygen influx during a typical discharge. The concentration of titanium in a discharge remained below that of nickel (from the Inconel surroundings). Coupled with this impurity reduction, $z_{\text {eff }}$ is lower, the bolometrically measured radiated power is lower, and the electron density limit for disruption free operation is higher.

\section{APPARATUS}

Two drive mechanisms for gettering operation are mounted on Doublet III, both at the same toroidal azimuth, one on the upper lobe of the chamber and the other on the lower. The upper is sketched in Fig. 1. Each mechanism supports two National Electrostatics Corporation 20 gram titanium getter cartridges mounted to a tantalum holder on the end of a stainless steel tube. This assembly is inside of a bellows having a usable stroke length of $\sim 1.3 \mathrm{~m}$. The getter cartridges are driven in and out of the vacuum chamber by a pneumatic air cylinder mounted outside the bellows.

Typically, the sequence for getter operation is as follows. Immediately after a plasma discharge the cartridges are driven into the central region of the chamber and the heaters turned on to bring the titanium to evaporation temperature. The rate of evaporation is in the range 0.04 to 0.10 grams per hour per cartridge. After 3-5 minutes the heaters are turned off, the cartridges allowed to cool for $45 \mathrm{sec}$ and then retracted prior to the next discharge. 
This level of gettering is relatively light, corresponding to at most $\sim 1 / 3$ of a surface-averaged monolayer of titanium evaporated each shot. The interior surface area of the vacuum vessel is $\sim 80 \mathrm{~m}^{2}$ and its volume $\sim 27 \mathrm{~m}^{3}$. A top view of the location of the inserted cartridges is shown in Fig. 2, together with the location of the primary limiters. Roughly $1 / 2$ of the vessel is in direct line-of-sight of the cartridges. The deposition pattern from the cartridges is nonuniform, having the pattern expected for the cylindrical sources with no emission from the ends.

The command logic for the getter drive and heat functions is preprogrammed in a Texas Instruments 5TI sequence controller. A full cycle is initiated by command from the Doublet III operations computer which controls the overall sequence necessary to prepare for a shot. Through this computer the operators are able to remotely set the cartridge heater currents and monitor these currents as well as other relevant getter system states.

Three different methods have been used to monitor the amount of titanium evaporated. First, extensive tests of the evaporation rate versus heater power were conducted on several cartridges in a tect chamber. The results were similar to the manufacturer's specifications. During gettering in Doublet. III a time record of the filament current is maintained, allowing computation of the amount evaporated based upon the test data. Second, a Kronos microbalance detector has been installed in the top of the vessel looking down on the location of the inserted cartridges. This is used to measure the accumulated titanium evaporated onto the detector. Finally, several in-situ tests have been performed to measure the amount of titanium collected by a surface sample placed at the radius of the outer wall on the upper lobe and azimuthally located as shown in Fig. 2. Results from these three methods are in good agreement. 


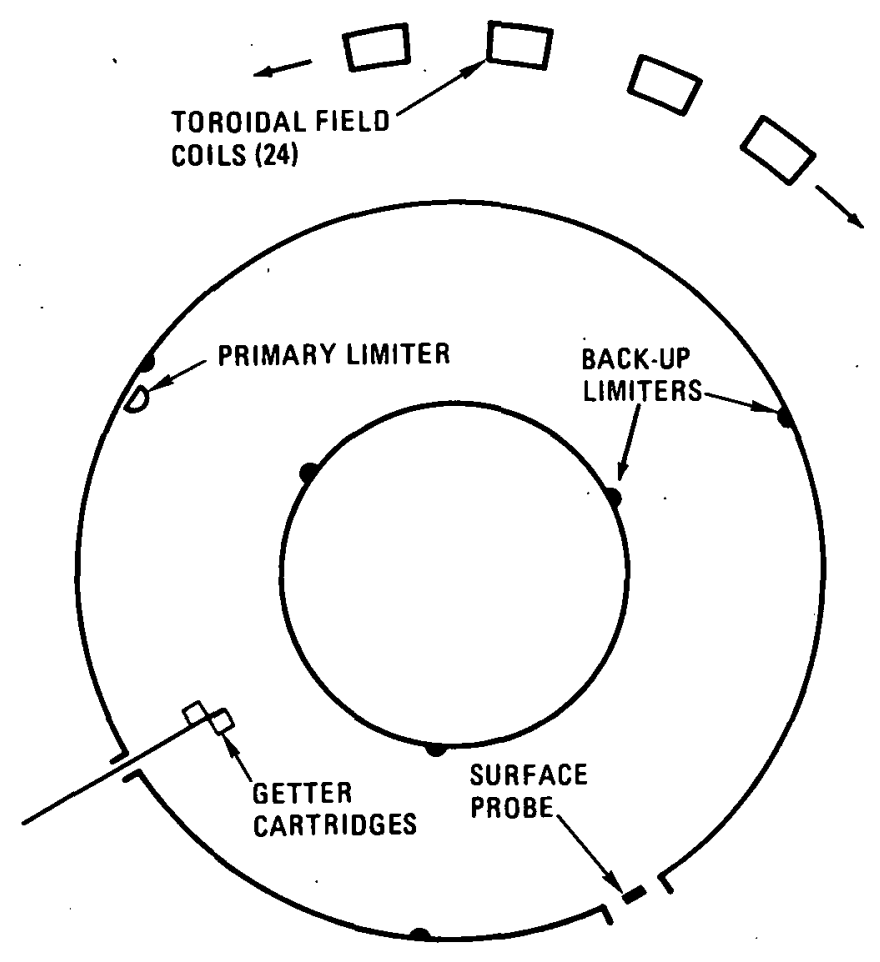

Fig. 2. Top view at the upper plane axis showing position of inserted getter cartridges 
In order to assess the effect of gettering on plasma impurities, several diagnostics are used: a VUV monochromator covering the wavelength range 300-10, a five-channel bolometer array on the upper plane, a twelve-channel tangentially viewing soft $\mathrm{X}$-ray array and the surface sample transfer and analysis station. This station permits the insertion and removal of one or more samples without perturbing the Doublet III vacuum conditions. The sample(s) can be transported, by remote control, approximately $7 \mathrm{~m}$ under ultrahigh vacuum to an analysis chamber located beyond the radiation shield wall surrounding the tokamak.

\section{RESULTS}

Titanium gettering has improved the characteristics of all of the many plasma shapes studied in Doublet III. At the time that gettering was initiated the JAERI physics team was running a dee-shaped discharge experiment to study the effect of gettering. The change was striking. on the first shot after lightly burning the getters for 20 min (deposit $\sim 0.06 \mathrm{gram}$ ) the one-turn voltage decreased by $\sim 30 \%$, indicating a $30 \%$ decrease in the electrical resistance of the discharge. The soft $x-r a y$ radiation from various regimes of the discharge decreased by a factor of two to five. Both physics teams have subsequently systematically investigated the effect of gettering.

Before and after values of $\mathrm{z}_{\text {eff }}$ calculated from plasma resistivity are plotted in Fig. 3 as a function of the line-averaged electron density $\left(\overline{\mathrm{n}}_{\mathrm{e}}\right)$ measured with $\mathrm{a} \mathrm{CO}_{2}$ laser interferometer system. The calculation assumes a safety factor of unity on axis since all discharges considered showed sawtooth oscillations. ${ }^{8}$ The value of $z$ eff was also estimated from the enhancement factor of the soft $\mathrm{x}$-ray radiation intensity and both results are in reasonable agreement. Clearly seen is the great 


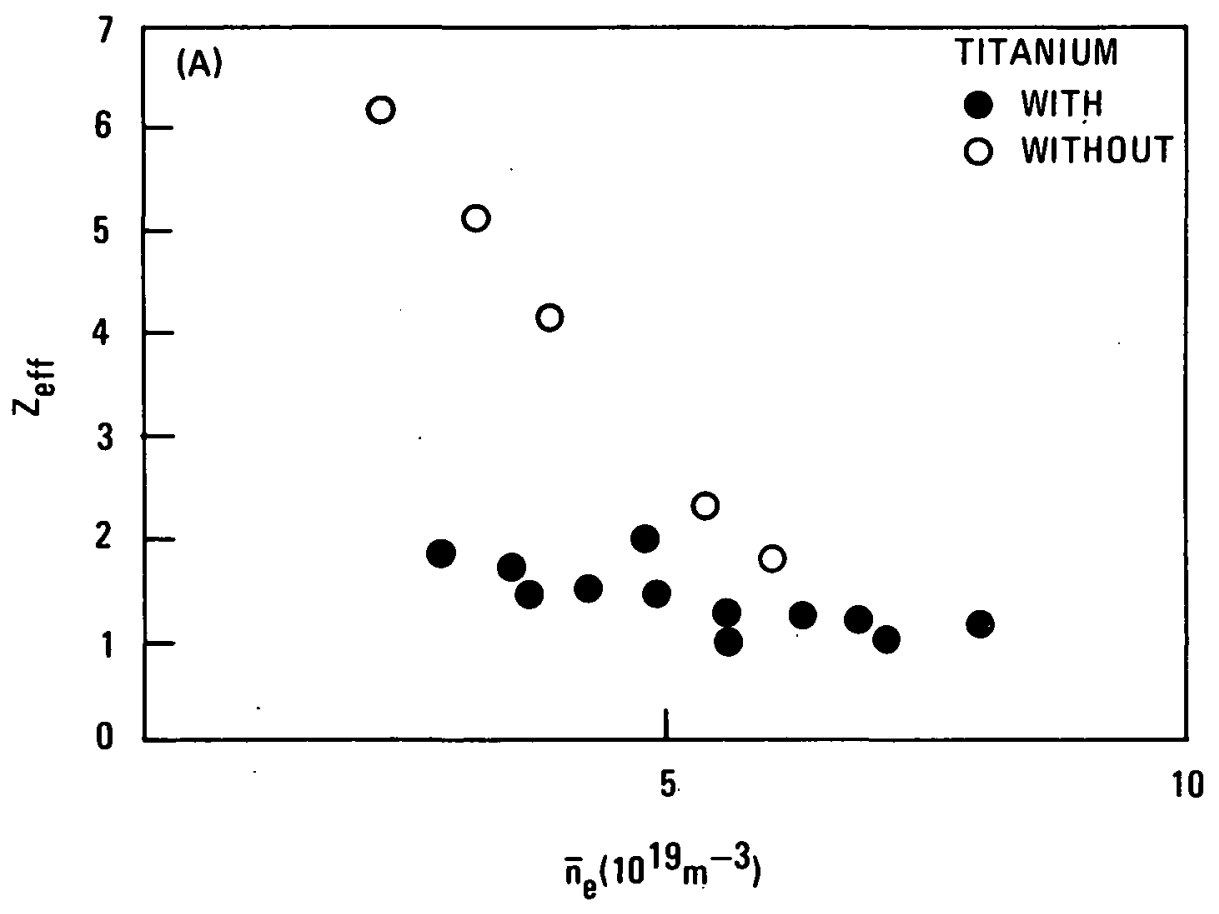

Fig. 3. Effective ionic charge $z_{\text {eff }}$ as a function of line-average plasma density $\bar{n}_{e}$ 
improvement of $z_{\text {eff }}$ with titanium gettering in the medium density region. These data are from JAERI dee discharges with plasma current $=0.5-0.7 \mathrm{MA}$, $\mathrm{B}_{\mathrm{T}}=2.0-2.4 \mathrm{~T}$, and an elongation $\mathrm{k}=1.2-1.5$. For cases with higher plasma current $z_{\text {eff }}$ is slightly higher.

The impurity most significantly reduced by gettering is oxygen. The level of ov radiation interpreted as a measure of the influx rate of oxygen, 9 decreased by a factor of five in the higher electron density regime. This relatively large reduction is compatible with the lowering of $z_{\text {eff }}$ to near unity since $\left(z_{\text {eff }}-1\right)$ is proportional to the impurity concentration (for constant $\mathrm{n}_{e}$ ).

The radiated power measured with the bolometer array has been greatly reduced. In the higher $\bar{n}_{e}$ cases the total radiated power has been reduced by nearly a factor of three. Prior to gettering, nearly all of the ohmic input power was lost by radiation in this high $\bar{n}_{e}$ regime.

This reduction in radiation for high density discharges has presumably led to the higher electron density limit subsequently achieved. The expanded linits for stable operation are shown in Fig. 4. The vertical axis is the inverse of the safety factor at the limiter, $q_{a}^{-1} \propto I_{p} / B_{T^{\prime}}$ and the horizontal axis is $\bar{n}_{e}$ expressed as a Murakami coefficient. ${ }^{10}$ Before and after gettering results are shown for both JAERI and GA experiments.3,11 The trend with gettering (filled in symbols) is for the stable operating limits to move upward (higher plasma current) and to the right (higher $\bar{n}_{e}$ ). There is an increase of approximately $40 \%$ in the maximum $\bar{n}_{e}$ detainable for each of the three configurations considered here.

Surface sample analyses have also measured the reduction of impurities and the deposition of titanium, as indicated in Fig. 5 for a silicon sample.12 The data points correspond to the total (Fig. 5a) or elemental (Fig. 5b and 5c) amount of material deposited in a 30 to 50 discharge exposure sequence. The sample was $\mathrm{Ar}^{+}$sputter cleaned immediately prior to each sequence. Titanium gettering was first used at discharge number 120 in Fig. 5, as exemplified by $\sim 0.5$ monolayers of Ti (i.e., 25\% of 


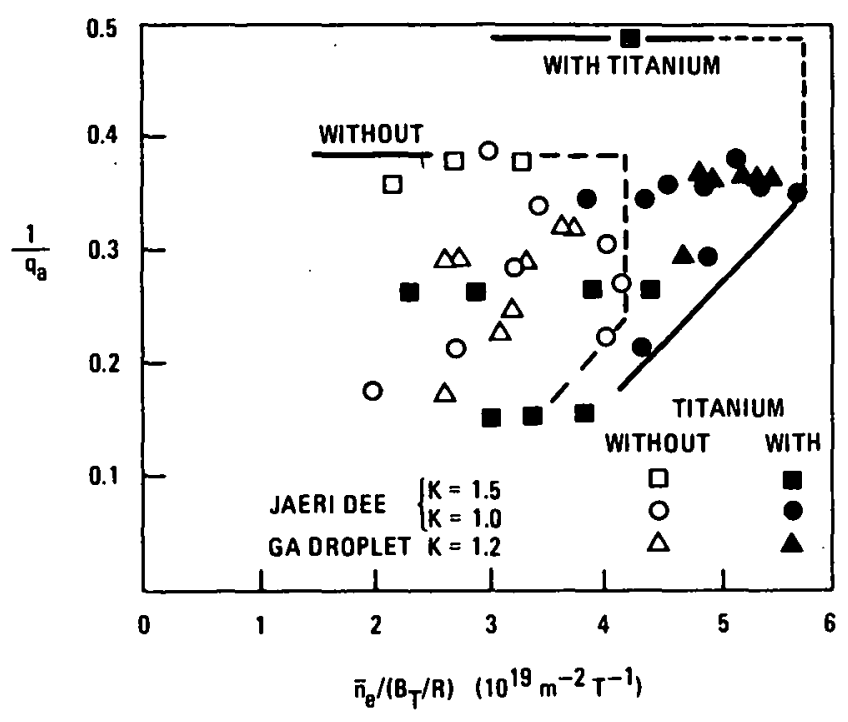

Fig. 4. Stable discharge region of surface safety factor $q_{a}$ and line-averaged density $\bar{n}_{\mathrm{e}}$ normalized to $\mathrm{B}_{\mathrm{T}} / \mathrm{R}$ 


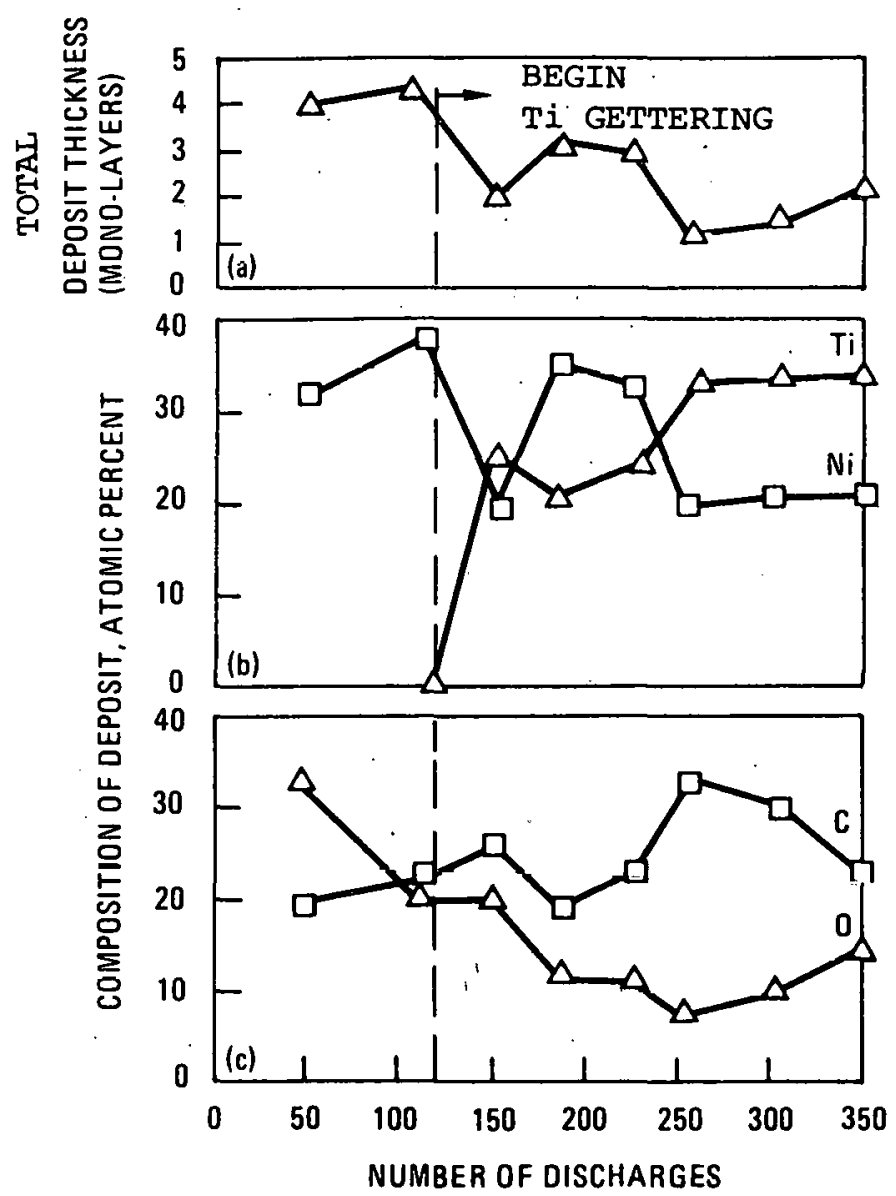

Fig. 5. Surface sample data showing the effect of titanium gettering 
2-monolayers of total deposit) on the sample after the succeeding 35 discharge sequence. Gettering reduced the amount of $\mathrm{N} i, \mathrm{O}$, and $\mathrm{C}$ moving around in a discharge. To see the carbon reduction from Fig. 5, recall that the absolute amount is equal to the product of the $\mathrm{C}$ percentage (Fig. 5c) and the total deposit (Fig. 5a). The amount of material deposited per shot cannot be inferred directly from Fig. 5. For example, in the case of $\mathrm{Ti}$ for the first post gettering sequence the apparent deposition rate is 0.5 monolayers $/ 35$ discharges $=1.48$ monolayer per discharge which is much less than expected from the getter evaporation rate. The reduction in the actual deposit is due to erosion of the probe deposit by the plasma discharge as discussed in reference 12 .

\section{CONCLUSION}

The use of mild titanium gettering in the Doublet III tokamak has resulted in a significant improvement of all of the many cross-sectional shaped discharges studied. Low-z impurities have been greatly reduced, with oxygen $V$ emission typically reduced by a factor of five. The maximum line averaged electron density has increased $50 \%\left(\overline{\mathrm{n}} \mathrm{e} \max \sim 1 \times 10^{14} / \mathrm{cc}\right)$ corresponding to a Murakami coefficient of nearly 6 . 


\section{REFERENCES}

${ }^{1}$ G. M. McCracken and P. E. stott, Nucl. Fusion 19, $889^{\prime}$ (1979).

${ }^{2}$ H. F. Dylla, Proceedings of the 4 th Intl. Conf. on Plasma Surf. Interactions in Contr. Fusion Devices, Garmish Partenkirchen (1980).

${ }^{3}$ A. Kitsunezaki et al., Proceedings of the 8 th Intl. Conf. on Plasma Phys. and contr. Fusion Research, Brussels (1980).

${ }^{4} \mathrm{~J}$. C. Wesley et al., Proceedings of the 8th Intl. Conf. on Plasma Phys. and Contr. Fusion Research, Brussels (1980).

${ }^{5}$. Ohyabu, Kaknyugo-Kenkyu 42,687 (1979).

${ }^{6} \mathrm{~L}$. Oren and R. J. Taylor, Nucl. Fusion 17, 1143 (1977) .

$7_{\mathrm{K}}$. Bol et al., Proceedings of the 7th Int1. Conf. on Plasma Phys. and Contr. Nucl. Fusion, p. 11 (1978).

${ }^{8}$ G. L. Jahns et al., Nucl. Fusion 18, 609 (1978).

9 EQUIPE TFR, Line Radiation in the Visible and Ultraviolet in TFR Tokamak Pleamas, EUR-CEA-EC-777 (1975).

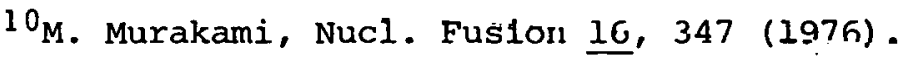

${ }^{11_{T}}$. Taylor et al., to be presented, 22nd Annual Meeting of the APS Division of Plasma Physics, San.Di.ego, California 1980.

$12 \mathrm{~J}$. N. Smith Jr, and C. H. Meyer Jr.; General Atomic Co. Report GA-A15874, and to be published, J. Vac. Sci. and Technol. 
Prof. R. J. Taylor

University of California-Los Angeles

405 Hilgard Avenue

Los Angeles, CA 90024

Princeton Plasma Physics Laboratory

Princeton University

P. 0. Box 451

Princeton, New Jersey 08540

One copy to each---above address

Oak Ridge National Laboratory

P. O. BoX Y

Oak Ridge, Tenn. 37830

One copy to each---above address

Dr. T. Sheffield

Dr. H. C. Howe

Dr. M. Murakami

Dr. Y-K. M. Peng

Dr. S. Milora

Dr. J. Bohdansky

Max-Planck-Institut für Plasma Physik D-8046, Garching bei München

Federal Republic of Germany

Dr. G. McCracken

Culham Laboratory

Abingdon, Bershire

England

Dr. C. R. Finfgeld

Applied Plasma Physics

Division of Magnetic Fusion Energy

Mail Stop G-234

U.S. Department of Energy

Washington, D.C. 20545

Dr. E. Oktay

Office of Fusion Energy

Department of Energy

Mail Stop G-234

Washington, D.C. 20545

Dr. N: A. Davies

Office of Fusion Energy

Department of Energy

Ma11 Stop G-234

Washington, D.C: 20545

Dr. E. S. Marmar

Massachusetts Institute of Technology

Cambridge, Mass. 02139

Dr. R. Parker

Massachusetts Institute of Technology

Cambridge, Mass. 02139

Prof. R. A. Gross

Columbia University

Department of Applied Physics and

Nuclear Engineering

New York, N.Y. 10027 


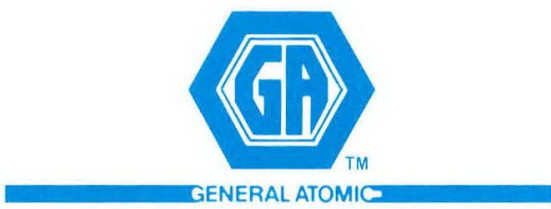

GENERAL ATOMIC COMPANY P. O. BOX 81608

SAN DIEGO, CALIFORNIA 92138 